\title{
Neural Correlates of Outcome of the Psychotherapy Compared to Antidepressant Therapy in Anxiety and Depression Disorders: A Meta-Analysis
}

\author{
Navkiran Kalsi ${ }^{1}$, Daniela Altavilla ${ }^{1 *}$, Renata Tambelli ${ }^{1}$, Paola Aceto ${ }^{2}$, Cristina Trentini ${ }^{1}$, \\ Chiara Di Giorgio ${ }^{1}$ and Carlo Lai ${ }^{1}$ \\ ${ }^{1}$ Department of Dynamic and Clinical Psychology, Sapienza University of Rome, Rome, Italy, ${ }^{2}$ Department of \\ Anaesthesiology and Intensive Care, Università Cattolica del Sacro Cuore, Rome, Italy
}

OPEN ACCESS

Edited by:

Rossella Guerini,

Roma Tre University, Italy

Reviewed by:

Gianluca Serafini, IRCCS San Martino Hospital,

University of Genoa, Italy Irene Messina

University of Padua, Italy

${ }^{*}$ Correspondence:

Daniela Altavilla

daniela.altavilla@uniroma1.it

Specialty section: This article was submitted to Theoretical and Philosophical Psychology,

a section of the journal Frontiers in Psychology

Received: 30 March 2017 Accepted: 19 May 2017

Published: 07 June 2017

Citation: Kalsi N, Altavilla $D$, Tambelli $R$, Aceto $P$, Trentini C, Di Giorgio C and Lai C (2017) Neural Correlates of Outcome

of the Psychotherapy Compared to Antidepressant Therapy in Anxiety and

Depression Disorders: A

Meta-Analysis. Front. Psychol. 8:927. doi: 10.3389/fpsyg.2017.00927
The most prevalent mental disorders, anxiety and depression, are commonly associated with structural and functional changes in the fronto-limbic brain areas. The clinical trials investigating patients with affective disorders showed different outcome to different treatments such as psychotherapy or pharmacotherapy. It is, however, still unexplored how these interventions approach affect the functional brain. This meta-analysis aims to compare the effects of psychotherapy compared to antidepressant therapy on functional brain activity in anxiety and depression disorders. Twenty-one samples with psychotherapy and seventeen samples with antidepressant therapy were included. The main finding showed an inverse effect of the two treatments on the right paracingulate activity. The patients undergoing psychotherapy showed an increase in the right paracingulate activity while pharmacological treatment led to a decrease of activation of this area. This finding seems to support the recent studies that hypothesize how psychotherapy, through the self-knowledge and the meaning processing, involves a top-down emotional regulation.

Keywords: psychotherapy, pharmacotherapy, neural correlates, anxiety, depression

\section{INTRODUCTION}

A human being is the outcome of a developing process, which depend on a complex interaction between the genetic information and the environment. A remarkable characteristic of the brain is that it allows the nervous system to process information from the interacting environment, modifying itself by experience in measurable ways (Markham and Greenough, 2004). With the recent advances in neuroimaging techniques, scientists are able to identify neural correlates not only of mental disorders but also of the changes associated with therapeutic interventions (Fuchs, 2004). These interventions are broadly categorized into psychotherapy or pharmaceutical treatments. However, it is very interesting to understand how the outcome of different treatments affect the functional brain activity and neural circuits (Salone et al., 2016).

The main impairment in affective disorders is related to emotional dysregulation and is characterized by abnormal brain activity in the cortico-limbic brain networks (Ochsner and Gross, 2008; Wager et al., 2008; Messina et al., 2013). Patients with depression showed hyperactivation 
of "default mode network" (DMN), consisting of the posterior cingulated, precuneus, inferior parietal lobule, medial prefrontal cortex, and of the amygdala during resting-state and in response to emotional stimuli (Greicius et al., 2007; Siegle et al., 2007; Grimm et al., 2009; Carlson et al., 2017). The patients with anxiety disorders showed multiple underlying structural abnormalities within the fear circuit, in particular of the ventromedial prefrontal cortex (Cha et al., 2014; Carlson et al., 2017) and an increased response in the amygdala, anterior cingulated cortex, and insula in anticipation of aversive and neutral stimuli (Stein et al., 2007; Nitschke et al., 2009; Carlson et al., 2011, 2017).

Accordingly, studies on the neurobiological outcomes of the therapeutic interventions in anxiety and depression disorders report the changes in neural activity in the cortico-limbic brain regions implicated in the emotion regulation (Ressler and Mayberg, 2007; Messina et al., 2013). With respect to prognosis and improvement of psychopathological symptoms, both psychotherapy and pharmacotherapy are clinically effective for treating psychopathological disorders (Cuijpers et al., 2013). Despite psychotherapy and pharmacotherapy seem to lead to a final common neurobiological pathway, it is reasonable to hypothesize that these widely differing treatments might engage diverse neural mechanisms (DeRubeis et al., 2008; Marano et al., 2012; Quidé et al., 2012). In according with this hypothesis, a recent meta-analysis showed that in patients with major depression the psychotherapy induced modifications in the left frontal, temporal, lingual gyri and in the cingulate cortex, as well as in the right frontal and precentral gyri. Otherwise, pharmacotherapy affected brain activation in the right insula (Boccia et al., 2016).

The pharmacotherapy is directly oriented to the emotional reactivity through the balance of neurotransmitter activity that seems to modify the neural activity in the limbic structures normalizing the cortical activity through bottom-up approach (Stahl, 2013). On the other side, the psychotherapy works on to build and to elaborate meanings that can regulate the attention and memory systems inducing changes in cortical brain activity that through top-down approach restores the limbic system functions reducing the emotional dysregulations (Linden, 2006).

Despite the impressive growth of neuroimaging techniques, how different treatments affect the functional brain is yet to be established.

In order to investigate the neural correlate of the outcome of different treatments used in the anxiety and depression clinical trials, in the present meta-analysis the therapeutic interventions were divided into two different categories: psychotherapy and antidepressant therapy.

The aim of the current meta-analysis was to compare the neural correlates of pre and post-treatment effects of psychotherapy and antidepressant therapy in affective disorders.

\section{METHODS}

In order to reach the aim of the meta-analysis, the following comparisons were performed: (1) pre- vs. post-treatment changes in the activations of brain regions due to psychotherapy (2) pre- vs. post-treatment changes in the activations of brain regions due to antidepressant therapy, and (3) post-treatment changes in the activations of brain regions due to psychotherapy vs. antidepressant therapy. Successively, the same contrasts only on resting state studies were re-performed. The significant effects for all contrasts were considered in both directions (increased and decreased effects post-treatment).

\section{Search Criterion}

A systematic search strategy was used to identify relevant neuroimaging studies reporting the changes in functional neural activity as a treatment outcome of cognitive/psychodynamic therapies and antidepressant therapy on the anxiety and depression disorders. For this purpose, PubMed and Scopus database search was performed by two independent researchers to find putative studies reporting the treatment for the anxiety and depression disorders following DSM-IV-TR criteria. The search was conducted for studies published between 2000 and 2016. The following search terms were used: "imaging," "fMRI" (functional MRI), "PET" (positron emission tomography), and "SPECT" (single photon emission computed tomography) in combination with the name of the disorder (anxiety, PTSD, panic disorder, phobias, and depression). Furthermore, the reference lists of the articles were manually checked for the studies not identified in earlier literature search. To achieve a high standard of reporting we have adopted "Preferred Reporting Items for Systematic Reviews and Meta-Analyses” (PRISMA) guidelines.

\section{Selection Criteria}

Studies were included if they met the following criteria: (a) being original papers in a peer-reviewed journal, (b) involving subjects with a pre and post-treatment effects, (c) having employed functional imaging, (d) having reported the brain coordinates in standard brain atlases, (e) having adult samples (age 18-65).

The studies in which the entire group of patients had received prior interventions at the time of the start of the treatment study and the studies which reported a single case study were not included in the meta-analysis to reduce the possible biases.

\section{Recorded Variables}

The variables recorded for articles in the meta-analysis were: sample size, gender, mean age of participants and peak coordinates reported along with the software and stereotactic space of these coordinates. Additionally, we recorded the statistical significance of the treatment outcomes and the method employed to correct the results for multiple comparisons. The studies which compared between two types of treatments (psychotherapy vs. antidepressant therapy), only the pre to post brain changes for each treatment separately were considered.

\section{Study Classification}

The studies were then classified into two categories based on the treatment type. The studies that included the cognitive (CT) and dynamic (DPT) based treatments were categorized in psychotherapy group, and those including the intake of antidepressant drugs in antidepressant therapy group (see Table 1). 
TABLE 1 | Studies included in meta-analysis.

\begin{tabular}{|c|c|c|c|c|c|c|}
\hline Study & Disease & Therapy & Patients & Technique & Task & Mean age \\
\hline Farrow et al., 2005 & PTSD & Psychotherapy & 13 & fMRI & Emotional task & 42 \\
\hline Felmingham et al., 2007 & PTSD & Psychotherapy & 8 & fMRI & Emotional task & 36.8 \\
\hline Fu et al., 2008 & Depression & Psychotherapy & 16 & fMRI & Emotional task & 40 \\
\hline Huang et al., 2014 & Depression & Psychotherapy & 23 & fMRI & Resting state & 27.7 \\
\hline Kircher et al., 2013 & Panic & Psychotherapy & 42 & fMRI & Emotional task & 35.42 \\
\hline Paquette et al., 2003 & Phobia & Psychotherapy & 12 & fMRI & Emotional task & 24.8 \\
\hline Ritchey et al., 2011 & Depression & Psychotherapy & 11 & fMRI & Emotional task & 36.1 \\
\hline Sakai et al., 2006 & Panic & Psychotherapy & 11 & PET & Resting state & 29.8 \\
\hline Schienle et al., 2007 & Phobia & Psychotherapy & 14 & fMRI & Emotional task & 27.2 \\
\hline Yoshimura et al., 2014 & Depression & Psychotherapy & 21 & fMRI & Emotional task & 37.3 \\
\hline Aupperle et al., 2013 & PTSD & Psychotherapy & 14 & fMRI & Emotional task & 40.1 \\
\hline Buchheim et al., 2012 & Depression & Psychotherapy & 16 & fMRI & Emotional task & 38.9 \\
\hline Wiswede et al., 2014 & Depression & Psychotherapy & 13 & fMRI & Emotional task & 39.8 \\
\hline Beutel et al., 2010 & Panic & Psychotherapy & 15 & fMRI & Emotional task & 32 \\
\hline Furmark et al., 2002 & Social Phobia & Psychotherapy; Antidepressant therapy & $6 ; 6$ & PET & Emotional task & 35.2 \\
\hline Goldapple et al., 2004 & Depression & Psychotherapy; Antidepressant therapy & $14 ; 13$ & PET & Resting state & $41 ; 36$ \\
\hline Kennedy et al., 2007 & Depression & Psychotherapy; Antidepressant therapy & $7 ; 9$ & PET & Resting state & $32.7 ; 40.1$ \\
\hline Konarski et al., 2009 & Depression & Psychotherapy; Antidepressant therapy & $7 ; 9$ & PET & Resting state & $32.7 ; 40.1$ \\
\hline Prasko et al., 2004 & Panic & Psychotherapy; Antidepressant therapy & $6 ; 6$ & PET & Resting state & $31.8 ; 32$ \\
\hline Brody et al., 2001 & Depression & Psychotherapy; Antidepressant therapy & $14 ; 10$ & PET & Resting state & $40.7 ; 36.4$ \\
\hline Martin et al., 2001 & Depression & Psychotherapy; Antidepressant therapy & $13 ; 15$ & SPECT & Resting state & $38.4 ; 39.4$ \\
\hline Brockmann et al., 2009 & Depression & Antidepressant therapy & 44 & SPECT & Resting state & 47.2 \\
\hline Carey et al., 2004 & Anxiety & Antidepressant therapy & 37 & SPECT & Resting state & 33.5 \\
\hline Kennedy et al., 2001 & Depression & Antidepressant therapy & 13 & PET & Resting state & 36.7 \\
\hline Mayberg et al., 2000 & Depression & Antidepressant therapy & 4 & PET & Resting state & 49 \\
\hline Samson et al., 2011 & Depression & Antidepressant therapy & 10 & fMRI & Emotional task & 41.5 \\
\hline Seedat et al., 2004 & PTSD & Antidepressant therapy & 11 & SPECT & Resting state & 33.6 \\
\hline Vlassenko et al., 2004 & Depression & Antidepressant therapy & 14 & SPECT & Resting state & 42.8 \\
\hline Warwick et al., 2006 & Anxiety & Antidepressant therapy & 31 & SPECT & Resting state & 33 \\
\hline Kilts et al., 2006 & Anxiety & Antidepressant therapy & 12 & PET & Emotional task & 38 \\
\hline Hoehn-Saric et al., 2004 & Anxiety & Antidepressant therapy & 6 & $\mathrm{fMRI}$ & Emotional task & 36 \\
\hline
\end{tabular}

In these studies, the brain activity was scanned during the resting-state, focuses on spontaneous, low frequency fluctuations in the BOLD signal (Lee et al., 2013), or during an emotional task, i.e., during emotionally arousing stimuli (Messina et al., 2013)."

\section{Standard Meta-Analyses of Functional Changes Post-treatment}

Voxel-based meta-analyses of functional brain changes to the treatment were conducted with the effect-size version of signed differential mapping (ES-SDM; Radua and Mataix-Cols, 2009, 2012). This technique has been used in meta-analysis studies on obsessive compulsive disorder, schizophrenia and bipolar disorder, etc. (Bora et al., 2010, 2011; Palaniyappan et al., 2012). This method is based on using the peak coordinates to recreate, for each study, a map of the effect sizes of the differences between pre and post-treatment changes in patients, and then on conducting a standard random-effects variance-weighted metaanalysis in each voxel.
Between group comparison among the two treatments (psychotherapy vs. antidepressant therapy) was conducted and significant results were reported after threshold at $p<0.001$ uncorrected (equivalent to $p<0.05$ corrected for multiple comparisons (Radua et al., 2010) with an extent threshold of $\mathrm{Ke}>$ 10 voxels. Default ES-SDM kernel size and thresholds were used (FWHM $=20 \mathrm{~mm}$, peak height $\mathrm{Z}=1$, cluster extent $=10$ voxels; Radua and Mataix-Cols, 2009).

Robustness of the significant results was assessed by means of exploration of the jack-knife analyses by systematically repeating the meta-analyses by excluding one study at a time. If a significant brain region remains significant in all or most of the combinations of studies it can be concluded that this finding is highly replicable.

\section{RESULTS}

Thirty-one studies met the inclusion criteria. Four-teen studies tested neural correlate of psychotherapy (eleven using CT, 
three DPT) and ten studies investigated neural correlate of antidepressant therapy. The remaining seven studies were performed on two randomized trial (five with CT vs. antidepressant therapy and two with DPT vs. antidepressant therapy). Thus, the meta-analysis included 16 samples reporting treatment outcomes with CT, 5 samples with DPT and 17 samples with antidepressant therapy. The overall sample was equivalent to a cohort of 546 individuals undergoing treatment for anxiety and depression (Mean age, $S D=36.3,5.46$ ) contributing data to the meta-analysis.

\section{Comparison of Regional Brain Response: Psychotherapy and Antidepressant Therapy}

Data for this analysis was obtained from 21 samples of 296 patients undergoing treatment with psychotherapy and 17 samples representing 250 patients undergoing antidepressant therapy.

As shown in Table 2, both psychotherapy and antidepressant therapy showed a decreased activation (post vs. pre) of the right inferior frontal gyrus, bilateral superior frontal gyrus, bilateral anterior cingulate, and right insula. However, other patterns of activations varied between these groups. In particular, patients undergoing psychotherapy showed an increased activation of right paracingulate gyrus and precuneus, and a decreased activation of right hippocampus, right parahippocampal gyrus, right amygdala, right rolandic operculum, right putamen, right temporal pole, right superior temporal gyrus, and bilateral anterior cingulate gyrus. Conversely, antidepressant therapy showed an increased activation (post vs. pre) in the right middle frontal gyrus, and a decreased activation of the bilateral supplementary motor area, bilateral paracingulate gyrus and bilateral caudate nucleus.

Interestingly, an inverse pattern of activation was observed in right paracingulate gyrus.

In order to control the effect of the task on the difference between outcome treatment of psychotherapy and antidepressant therapy, a comparison between the two treatments on only the resting state studies was conducted. Data for this analysis was obtained from 15 resting state studies representing 8 samples with 95 patients undergoing treatment with psychotherapy $(25 \%$ anxiety and 75\% depression disorders) and 11 samples with 192 patients undergoing antidepressant therapy (36\% anxiety and $64 \%$ depression disorders). The findings confirm the inverse pattern of activation observed in right paracingulate gyrus in the previous analyses (Table 2 ).

\section{Robustness Analysis}

The analysis of robustness (jack-knife sensitivity analyses) showed that the results were highly replicable with possible exception of right parahippocampal gyrus, right superior frontal gyrus and bilateral caudate nucleus in antidepressant therapy group, and with possible exception of the left middle frontal activation in psychotherapy trials where this activation did not remain significant in 10/21 re-sampling combination trials.

\section{DISCUSSION}

This is to our knowledge is the first neuroimaging meta-analysis which focuses on a comparison between psychotherapy and antidepressant therapy in patients with anxiety and depression.

The patients undergoing psychotherapeutic and pharmacological treatments for anxiety and depression showed an overall decreased activations in right inferior frontal gyrus, bilateral superior frontal gyrus, bilateral anterior cingulate and right insula suggesting the relevant role of these areas in the symptoms reduction. Superior frontal gyrus and anterior cingulate represent the components of central executive networks of information processing which is activated when performing a task requiring focused attention. Furthermore, anterior cingulate and insula are involved in the Salience Network (Ham et al., 2013) which is responsible for switching between the default mode network (the network which is active during the rest when the brain is not engaged in a specific task) and the central executive network (Goulden et al., 2014). The intensity of interactions of default mode and central executive network in insular salience network activity have been previously associated with the severity of symptoms in major depressive disorder (Manoliu et al., 2013). The reduced post-treatment activations of these areas in anxiety and depression could indicate the restored activity of the brain.

The main finding of the present study was the inverse effects of psychotherapy and antidepressant therapy on the right paracingulate activity. The patients undergoing psychotherapeutic treatment led to an increased activation of the right paracingulate activity while those with antidepressant therapy showed a decrease of this area. The paracingulate cortex (approximately corresponding to BA32) is often considered to be part of the anterior cingulate cortex, however the BA32 has been described cytoarchitectonically as a cingulo-frontal transition area (Devinsky et al., 1995) and therefore anatomically (and maybe functionally) distinct from the anterior cingulated cortex (Gallagher and Frith, 2003). Specially, the paracingulate cortex activity seems to be associated with the mentalizing ability (Gallagher and Frith, 2003) and with self-monitoring such as: visual self-recognition (Kircher et al., 2000, 2001), autobiographical memory (Maguire and Mummery, 1999; Maguire, 2001), conflict monitoring (Botvinick et al., 2001; Beckmann et al., 2009), verbal self-monitoring (McGuire et al., 1996b), self-generated thoughts (McGuire et al., 1996a). The components of these abilities are implicated in initiation and maintenance of the symptoms of anxiety and depression (Roiser et al., 2012; Weightman et al., 2014; Anastasides et al., 2015; Bartczak and Bokus, 2015). Moreover, a study showed that the paracingulate cortex is active during the "rest" condition (Gusnard et al., 2001). The authors suggested that this might indicate a "default" mode of functioning in which "we think about ourselves" (Gusnard et al., 2001). In light of these findings, it seems that cingulo-frontal section could be specialized on internal mental states processing (Gallagher and Frith, 2003).

In a very interesting way, different authors reported that the anterior cingulated cortex is evolutionally very recent, in fact, it is present only in humans and in higher primates (Nimchinsky 


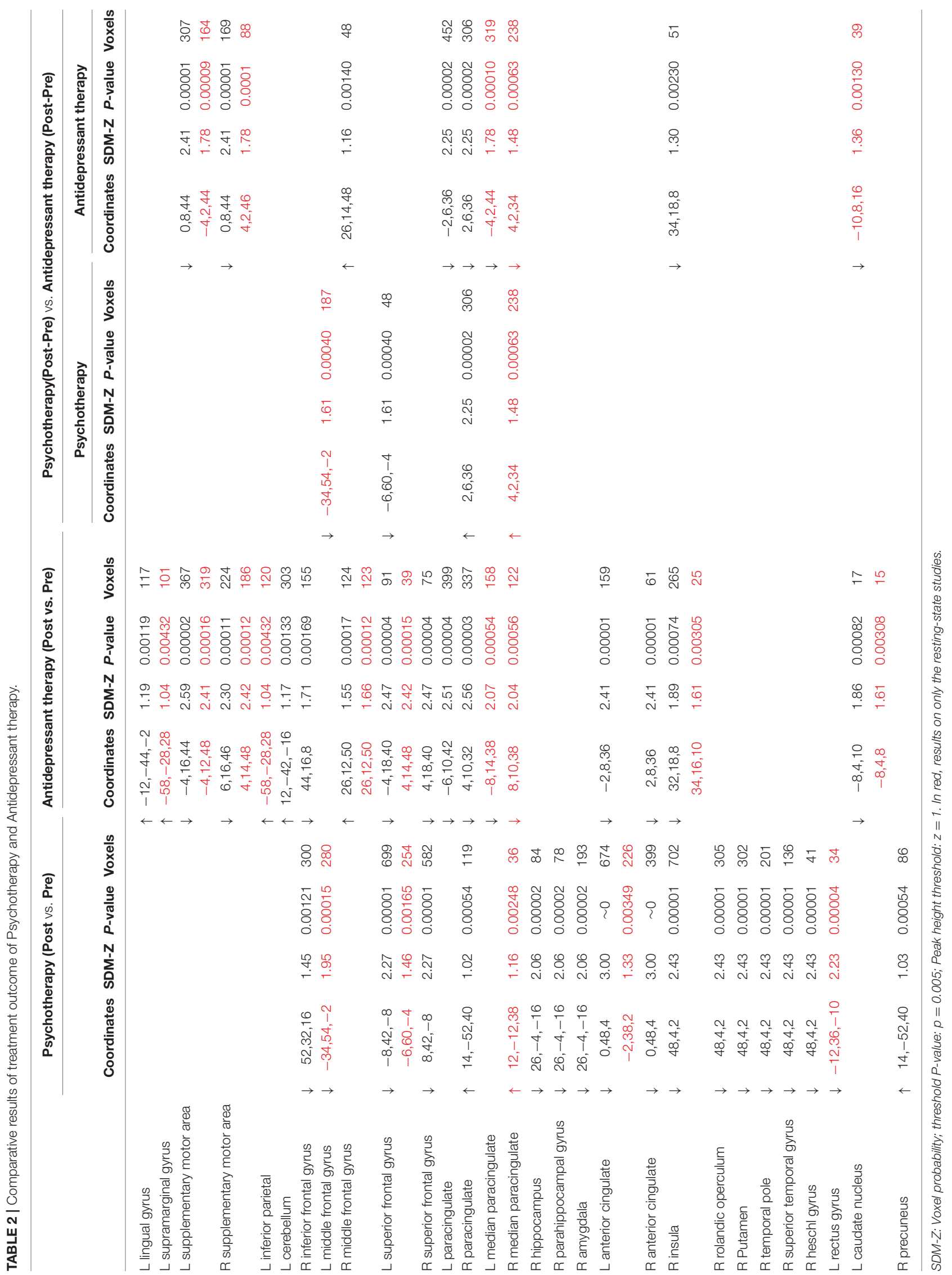


et al., 1999). Specifically paracingulate cortex seems to be present only in 50\% of humans (Paus, 2001) and it might be indicative of a progressive evolution of this region in humans (Zilles et al., 1988; Gallagher and Frith, 2003), suggesting as its development could be affected by the environment and by the relative meaning attribution.

In line with the theoretical aspects of psychotherapies that emphasize the importance of the internal reality, as the representations, and the processes of the meaning attribution and elaboration (Timary et al., 2011), the increase of the right paracingulate activity might be interpreted as psychotherapy conditioned increase of the attention to personal inner states and of the emotions regulation ability (Keune et al., 2012; Messina et al., 2016).

Moreover, through the introspection and the self-knowledge, "a subject can construct itself as psychologically self-conscious (and not only as physically self-conscious) in an interplay of meta-representational abilities, autobiographical memory, and socio-communicative capacities" (Guerini et al., 2015). Conversely, the neurobiological outcome of the antidepressant therapy showed a decrease of the right paracingulate activity, which can be explained by the fact that this kind of treatment is not focused on the elaboration of internal mental states.

An alternative interpretation is that the inverse effect of the two types of treatment could be due to the different experimental tasks used during the neurobiological data acquisition (Messina et al., 2013). The results of the meta-analyses including only resting state studies, where the inverse effect of psychotherapy vs. antidepressant therapy on paracingulate activity was maintained, it falsifies this interpretation.

\section{Limitations}

The present meta-analysis entails certain limitations. First, methodological limitation concerns the data available for analysis. Several studies had small sample sizes, variable duration, heterogeneity of techniques and study designs which might affect the outcome of the therapeutic outcome and thus the quality of the meta-analysis.

\section{REFERENCES}

Anastasides, N., Beck, K. D., Pang, K. C. H., Servatius, R. J., Gilbertson, M. W., Orr, S. P., et al. (2015). Increased generalization of learned associations is related to re-experiencing symptoms in veterans with symptoms of post-traumatic stress. Stress 18, 484-489. doi: 10.3109/10253890.2015.1053450

Aupperle, R. L., Allard, C. B., Simmons, A. N., Flagan, T., Thorp, S. R., Norman, S. B., et al. (2013). Neural responses during emotional processing before and after cognitive trauma therapy for battered women. Psychiat. Res. 214, 48-55. doi: 10.1016/j.pscychresns.2013.05.001

Bartczak, M., and Bokus, B. (2015). Cognitive Representations (Metaphorical Conceptualizations) of PAST, FUTURE, JOY, SADNESS and HAPPINESS in depressive and non-depressive subjects: cognitive distortions in depression at the level of notion. J. Psycholinguist. Res. 44, 159-185. doi: 10.1007/s10936-014-9286-6

Beckmann, M., Johansen-Berg, H., and Rushworth, M. F. (2009). Connectivity-based parcellation of human cingulate cortex and its relation to functional specialization. J. Neurosci. 29, 1175-1190. doi: 10.1523/JNEUROSCI.3328-08.2009
A second limitation is the considerable heterogeneity in the samples due to the combination of anxiety and depression together. However, in order to reduce the pathology biases, we considered homogeneous number of studies for anxiety and depression in psychotherapy and antidepressant therapy studies. Another limitation is that this meta-analysis also includes the studies reporting only the region of interest involving fronto-limbic brain. Finally, the present meta-analysis did not compare different types of psychotherapies (cognitive vs. dynamic). This lack was due to the exiguous number of clinical samples treated with dynamic psychotherapy. In order to perform this comparison more studies on the neurobiological outcome of dynamic treatment are needed.

\section{CONCLUSIONS}

The finding of the present meta-analysis showed a different neurobiological outcome of the psychotherapy compared to antidepressant therapy in anxiety and depression. The psychotherapeutic and pharmacological treatments showed inverse effects on the right paracingulate activity. This finding seems to support the recent studies (Linden, 2006) that hypothesize how psychotherapy, through the self-knowledge and the meaning processing, involves a top-down emotional regulation.

\section{AUTHOR CONTRIBUTIONS}

Participated in meta-analysis design: CL and NK. Performed data analysis: NK. Wrote or contributed to the writing of the manuscript: NK, DA, RT, PA, CT, CD, and CL.

\section{ACKNOWLEDGMENTS}

We thank Marco Cecchini for his valuable comments on earlier versions of the manuscript and constructive input in the revised manuscript.

Beutel, M. E., Stark, R., Pan, H., Silbersweig, D., and Dietrich, S. (2010). Changes of brain activation pre- post short-term psychodynamic inpatient psychotherapy: an fMRI study of panic disorder patients. Psychiat. Res. 184, 96-104. doi: 10.1016/j.pscychresns.2010. 06.005

Boccia, M., Piccardi, L., and Guariglia, P. (2016). How treatment affects the brain: meta-analysis evidence of neural substrates underpinning drug therapy and psychotherapy in major depression. Brain Imaging Behav. 10, 619-627. doi: 10.1007/s11682-015-9429-x

Bora, E., Fornito, A., Radua, J., Walterfang, M., Seal, M., Wood, S. J., et al. (2011). Neuroanatomical abnormalities in schizophrenia: a multimodal voxelwise meta-analysis and meta-regression analysis. Schizophr. Res. 127, 46-57. doi: 10.1016/j.schres.2010.12.020

Bora, E., Fornito, A., Yücel, M., and Pantelis, C. (2010). Voxelwise meta-analysis of gray matter abnormalities in bipolar disorder. Biol. Psychiatry 67, 1097-1105. doi: 10.1016/j.biopsych.2010.01.020

Botvinick, M. M., Braver, T. S., Barch, D. M., Carter, C. S., and Cohen, J. D. (2001). Conflict monitoring and cognitive control. Psychol. Rev. 108, 624-652. doi: 10.1037/0033-295X.108.3.624 
Brockmann, H., Zobel, A., Joe, A., Biermann, K., Scheef, L., Schuhmacher, A., et al. (2009). The value of HMPAO SPECT in predicting treatment response to citalopram in patients with major depression. Psychiatry Res. 173, 107-112. doi: 10.1016/j.pscychresns.2008.10.006

Brody, A. L., Saxena, S., Stoessel, P., Gillies, L. A., Fairbanks, L. A., Alborzian, S., et al. (2001). Regional brain metabolic changes in patients with major depression treated with either paroxetine or interpersonal therapy: preliminary findings. Arch. Gen. Psychiatry 58, 631-640. doi: 10.1001/archpsyc. 58.7.631

Buchheim, A., Viviani, R., Kessler, H., Kächele, H., Cierpka, M., Roth, G., et al. (2012). Changes in prefrontal-limbic function in major depression after 15 Months of long-term psychotherapy. PLoS ONE 7:e33745. doi: 10.1371/journal.pone.0033745

Carey, P. D., Warwick, J., Niehaus, D. J., van der Linden, G., van Heerden, B. B., Harvey, B. H., et al. (2004). Single photon emission computed tomography (SPECT) of anxiety disorders before and after treatment with citalopram. BMC Psychiatry 4:30. doi: 10.1186/1471-244X-4-30

Carlson, J. M., Greenberg, T., Rubin, D., and Mujica-Parodi, L. R. (2011). Feeling anxious: anticipatory amygdalo-insular response predicts the feeling of anxious anticipation. Soc. Cogn. Affect Neurosci. 6, 74-81. doi: 10.1093/scan/ nsq017

Carlson, J. M., Rubin, D., and Mujica-Parodi, L. R. (2017). Lost emotion: disrupted brain-based tracking of dynamic affective episodes in anxiety and depression. Psychiatry Res. 260, 37-48. doi: 10.1016/j.pscychresns.2016. 12.002

Cha, J., Greenberg, T., Carlson, J. M., DeDora, D. J., Hajcak, G., and MujicaParodi, L. R. (2014). Circuit-wide structural and functional measures predict ventromedial prefrontal fear generalization:generalization: implications for generalized anxiety disorder. J. Neurosci. 34, 4043-4053. doi: 10.1523/ JNEUROSCI.3372-13.2014

Cuijpers, P., Sijbrandij, M., Koole, S. L., Andersson, G., Beekman, A. T., and Reynolds, C. F. (2013). The efficacy of psychotherapy and pharmacotherapy in treating depressive and anxiety disorders: a meta-analysis of direct comparisons. World Psychiatry 12, 137-148. doi: 10.1002/wps. 20038

DeRubeis, R. J., Siegle, G. J., and Hollon, S. D. (2008). Cognitive therapy versus medication for depression: treatment outcomes and neural mechanisms. Nat. Rev. Neurosci. 9, 788-796. doi: 10.1038/nrn2345

Devinsky, O., Morrell, M. J., and Vogt, B. A. (1995). Contributions of anterior cingulate cortex to behaviour. Brain 118, 279-306. doi: 10.1093/brain/ 118.1.279

Farrow, T. F. D., Hunter, M. D., Wilkinson, I. D., Gouneea, C., Fawbert, D., Smith, R., et al. (2005). Quantifiable change in functional brain response to empathic and forgivability judgments with resolution of posttraumatic stress disorder. Psychiatry Res. 140, 45-53. doi: 10.1016/j.pscychresns.2005. 05.012

Felmingham, K., Kemp, A., Williams, L., Das, P., Hughes, G., Peduto, A., et al. (2007). Changes in Anterior Cingulate and Amygdala after Cognitive Behavior Therapy of Posttraumatic Stress Disorder. Psychol. Sci. 18, 127-129. doi: 10.1111/j.1467-9280.2007.01860.x

Fu, C. H. Y., Williams, S. C. R., Cleare, A. J., Scott, J., Mitterschiffthaler, M. T., Walsh, N. D., et al. (2008). Neural responses to sad facial expressions in major depression following cognitive behavioral therapy. Biol. Psychiatry 64, 505-512. doi: 10.1016/j.biopsych.2008.04.033

Fuchs, T. (2004). Neurobiology and psychotherapy: an emerging dialogue. Curr. Opin. Psychiatry 17, 479-485. doi: 10.1097/00001504-200411000-00010

Furmark, T., Tillfors, M., Marteinsdottir, I., Fischer, H., Pissiota, A., and Långström, B. (2002). Common changes in cerebral blood flow in patients with social phobia treated with citalopram or cognitive-behavioral therapy. Arch. Gen. Psychiatry 59, 425-433. doi: 10.1001/archpsyc.59.5.425

Gallagher, H. L., and Frith, C. D. (2003). Functional imaging of "theory of mind." Trends Cogn. Sci. 7, 77-83. doi: 10.1016/S1364-6613(02)00025-6

Goldapple, K., Segal, Z., Garson, C., Lau, M., Bieling, P., Kennedy, S., et al. (2004). Modulation of cortical-limbic pathways in major depression: treatmentspecific effects of cognitive behavior therapy. Arch. Gen. Psychiatry 61, 34-41. doi: 10.1001/archpsyc.61.1.34

Goulden, N., Khusnulina, A., Davis, N. J., Bracewell, R. M., Bokde, A. L., McNulty, J. P., et al. (2014). The salience network is responsible for switching between the default mode network and the central executive network: replication from DCM. NeuroImage 99, 180-190. doi: 10.1016/j.neuroimage.2014.05.052

Greicius, B. H., Flores, V., Menon, G. H., Glover, H. B., Solvason, H., Kenna, A. L., et al. (2007). Schatzberg resting-state functional connectivity in major depression: abnormally increased contributions from subgenual cingulate cortex and thalamus. Biol. Psychiatry 62, 429-437. doi: 10.1016/j.biopsych.2006. 09.020

Grimm, S., Boesiger, P., Beck, J., Schuepbach, D., Bermpohl, F., Walter, M., et al. (2009). Altered negative BOLD responses in the default-mode network during emotion processing in depressed subjects. Neuropsychopharmacology 34, 932-943. doi: 10.1038/npp.2008.81

Guerini, R., Marraffa, M., and Paloscia, C. (2015). Mentalization, attachment, and subjective identity. Front. Psychol. 6:1022. doi: 10.3389/fpsyg.2015.01022

Gusnard, D. A., Akbudak, E., Shulman, G. L., and Raichle, M. E. (2001). Medial prefrontal cortex and selfreferential mental activity: relation to a default mode of brain function. Proc. Natl. Acad. Sci. U.S.A. 98, 4259-4264. doi: 10.1073/pnas.071043098

Ham, T., Leff, A., Boissezon, X., de Boissezon, Joffe, A., and Sharp, D. J. (2013). Cognitive control and the salience network: an investigation of error processing and effective connectivity. J. Neurosci. 33, 7091-7098. doi: 10.1523/ JNEUROSCI.4692-12.2013

Hoehn-Saric, R., Schlund, M. W., and Wong, S. H. Y. (2004). Effects of citalopram on worry and brain activation in patients with generalized anxiety disorder. Psychiatry Res. 131, 11-21. doi: 10.1016/j.pscychresns.2004. 02.003

Huang, X., Huang, P., Li, D., Zhang, Y., Wang, T., Mu, J., et al. (2014). Early brain changes associated with psychotherapy in major depressive disorder revealed by resting-state fMRI: evidence for the top-down regulation theory. Int. J. Psychophysiol. 94, 437-444. doi: 10.1016/j.ijpsycho.2014. 10.011

Kennedy, S. H., Evans, K. R., Krüger, S., Mayberg, H. S., Meyer, J. H., McCann, S., et al. (2001). Changes in regional brain glucose metabolism measured with positron emission tomography after paroxetine treatment of major depression. Am. J. Psychiatry 158, 899-905. doi: 10.1176/appi.ajp.158. 6.899

Kennedy, S. H., Konarski, J. Z., Segal, Z. V., Lau, M. A., Bieling, P. J., McIntyre, R. S., et al. (2007). Differences in brain glucose metabolism between responders to $\mathrm{CBT}$ and venlafaxine in a 16 -week randomized controlled trial. Am. J. Psychiatry 164, 778-788. doi: 10.1176/ajp.2007.164.5.778

Keune, P. M., Bostanov, V., Kotchoubey, B., and Hautzinger, M. (2012). Mindfulness versus rumination and behavioral inhibition: a perspective from research on frontal brain asymmetry. Pers. Individ. Dif. 53, 323-328. doi: 10.1016/j.paid.2012.03.034

Kilts, C. D., Kelsey, J. E., Knight, B., Ely, T. D., Bowman, F. D., Gross, R. E., et al. (2006). The neural correlates of social anxiety disorder and response to pharmacotherapy. Neuropsychopharmacology 31, 2243-2253. doi: 10.1038/sj.npp.1301205

Kircher, T., Arolt, V., Jansen, A., Pyka, M., Reinhardt, I., Kellermann, T., et al. (2013). Effect of cognitive-behavioral therapy on neural correlates of fear conditioning in panic disorder. Biol. Psychiatry 73, 93-101. doi: 10.1016/j.biopsych.2012.07.026

Kircher, T. T. J., Senior, C., Phillips, M. L., Benson, P. J., Bullmore, E. T., Brammer, M., et al. (2000). Towards a functional neuroanatomy of self processing: effects of faces and words. Cogn. Brain Res. 10, 133-144. doi: 10.1016/S0926-6410(00)00036-7

Kircher, T. T., Senior, C., Phillips, M. L., Rabe-Hesketh, S., Benson, P. J., Bullmore, E. T., et al. (2001). Recognizing one's own face. Cognition 78, B1-B15. doi: 10.1016/S0010-0277(00)00104-9

Konarski, J. Z., Kennedy, S. H., Segal, Z. V., Lau, M. A., Bieling, P. J., McIntyre, R. S., et al. (2009). Predictors of nonresponse to cognitive behavioural therapy or venlafaxine using glucose metabolism in major depressive disorder. J. Psychiatry Neurosci. 34, 175-180.

Lee, M. H., Smyser, C. D., and Shimony, J. S. (2013). Resting state fMRI: a review of methods and clinical applications. Am. J. Neuroradiol. 34, 1866-1872. doi: 10.3174/ajnr.A3263

Linden, D. E. J. (2006). How psychotherapy changes the brain-the contribution of functional neuroimaging. Mol. Psychiatry 11, 528-538. doi: $10.1038 /$ sj.mp.4001816 
Maguire, E. A. (2001). Neuroimaging studies of autobiographical event memory. Philos. Trans. R. Soc. Lond. B Biol. Sci. 356, 1441-1451. doi: 10.1098/rstb.2001. 0944

Maguire, E. A., and Mummery, C. J. (1999). Differential modulation of a common memory retrieval network revealed by positron emission tomography. Hippocampus 9, 54-61. doi: 10.1002/(SICI)1098-1063(1999)9:1<54::AIDHIPO6>3.0.CO;2-O

Manoliu, A., Meng, C., Brandl, F., Doll, A., Tahmasian, M., Scherr, M., et al. (2013). Insular dysfunction within the salience network is associated with severity of symptoms and aberrant inter-network connectivity in major depressive disorder. Front. Hum. Neurosci. 7:930. doi: 10.3389/fnhum.2013.00930

Marano, G., Traversi, G., Nannarelli, C., Pitrelli, S., Mazza, S., and Mazza, M. (2012). Functional neuroimaging: points of intersection between biology and psychotherapy. Clin Ter. 163, e443-e456.

Markham, J. A., and Greenough, W. T. (2004). Experience-driven brain plasticity: beyond the synapse. Neuron Glia Biol. 1, 351-363. doi: 10.1017/S1740925X050 00219

Martin, S. D., Martin, E., Rai, S. S., Richardson, M. A., and Royall, R. (2001). Brain blood flow changes in depressed patients treated with interpersonal psychotherapy or venlafaxine hydrochloride: Preliminary findings. Arch. Gen. Psychiatry 58, 641-648. doi: 10.1001/archpsyc. 58.7.641

Mayberg, H. S., Brannan, S. K., Tekell, J. L., Silva, J. A., Mahurin, R. K., McGinnis, S., et al. (2000). Regional metabolic effects of fluoxetine in major depression: serial changes and relationship to clinical response. Biol. Psychiatry 48, 830-843. doi: 10.1016/S0006-3223(00)01036-2

McGuire, P. K., Paulesu, E., Frackowiak, R. S., and Frith, C. D. (1996a). Brain activity during stimulus independent thought. NeuroReport 7, 2095-2099.

McGuire, P. K., Silbersweig, D. A., and Frith, C. D. (1996b). Functional neuroanatomy of verbal self-monitoring. Brain 119, 907-917. doi: 10.1093/ brain/119.3.907

Messina, I., Sambin, M., Beschoner, P., and Viviani, R. (2016). Changing views of emotion regulation and neurobiological models of the mechanism of action of psychotherapy. Cogn. Affect. Behav. Neurosci. 16, 571-587. doi: 10.3758/s13415-016-0440-5

Messina, I., Sambin, M., Palmieri, A., and Viviani, R. (2013). Neural correlates of psychotherapy in anxiety and depression: a meta-analysis. Plos ONE 8:e74657. doi: 10.1371/journal.pone.0074657

Nimchinsky, E. A., Gilissen, E., Allman, J. M., Perl, D. P., Erwin, J. M., and Hof, P. R. (1999). A neuronal morphologic type unique to humans and great apes. Proc. Natl. Acad. Sci. U.S.A. 96, 5268-5273. doi: 10.1073/pnas.96. 9.5268

Nitschke, J. B., Sarinopoulos, I., Oathes, D. J., Johnstone, T., Whalen, P. J., Davidson, R. J., et al. (2009). Anticipatory activation in the amygdala and anterior cingulate in generalized anxiety disorder and prediction of treatment response. Am. J. Psychiatry 166, 302-310. doi: 10.1176/appi.ajp.2008.07101682

Ochsner, K. N., and Gross, J. J. (2008). Cognitive emotion regulation insights from social cognitive and affective neuroscience. Curr. Dir. Psychol. Sci. 17, 153-158. doi: $10.1111 / j .1467-8721.2008 .00566 . x$

Palaniyappan, L., Balain, V., Radua, J., and Liddle, P. F. (2012). Structural correlates of auditory hallucinations in schizophrenia: a meta-analysis. Schizophr. Res. 137, 169-173. doi: 10.1016/j.schres.2012.01.038

Paquette, V., Lévesque, J., Mensour, B., Leroux, J. M., Beaudoin, G., Bourgouin, P., et al. (2003). Change the mind and you change the brain: effects of cognitivebehavioral therapy on the neural correlates of spider phobia. NeuroImage 18, 401-409. doi: 10.1016/S1053-8119(02)00030-7

Paus, T. (2001). Primate anterior cingulate cortex: where motor control, drive and cognition interface. Neuroscience 2, 417-424. doi: 10.1038/35077500

Prasko, J., Horácek, J., Záleský, R., Kopecek, M., Novák, T., Pasková, B., et al. (2004). The change of regional brain metabolism (18FDG PET) in panic disorder during the treatment with cognitive behavioral therapy or antidepressants. Neuro Endocrinol. Lett. 25, 340-348.

Quidé, Y., Witteveen, A. B., El-Hage, W., Veltman, D. J., and Olff, M. (2012). Differences between effects of psychological versus pharmacological treatments on functional and morphological brain alterations in anxiety disorders and major depressive disorder: a systematic review. Neurosci. Biobehav. Rev. 36, 626-644. doi: 10.1016/j.neubiorev.2011.09.004
Radua, J., and Mataix-Cols, D. (2009). Voxel-wise meta-analysis of grey matter changes in obsessive-compulsive disorder. Br. J. Psychiatry 195, 393-402. doi: 10.1192/bjp.bp.108.055046

Radua, J., and Mataix-Cols, D. (2012). Meta-analytic methods for neuroimaging data explained. Biol. Mood Anxiety Disord. 2:6. doi: 10.1186/2045-5380-2-6

Radua, J., van den Heuvel, O. A., Surguladze, S., and Mataix-Cols, D. (2010). Meta-analytical comparison of voxel-based morphometry studies in obsessivecompulsive disorder vs. other anxiety disorders. Arch. Gen. Psychiatry 67, 701-711. doi: 10.1001/archgenpsychiatry.2010.70

Ressler, K. J., and Mayberg, H. S. (2007). Targeting abnormal neural circuits in mood and anxiety disorders: from the laboratory to the clinic. Nat. Neurosci. 10, 1116-1124. doi: 10.1038/nn1944

Ritchey, M., Dolcos, F., Eddington, K. M., Strauman, T. J., and Cabeza, R. (2011). Neural correlates of emotional processing in depression: changes with cognitive behavioral therapy and predictors of treatment response. J. Psychiat. Res. 45, 577-587. doi: 10.1016/j.jpsychires.2010.09.007

Roiser, J. P., Elliott, R., and Sahakian, B. J. (2012). Cognitive mechanisms of treatment in depression. Neuropsychopharmacology 37, 117-136. doi: $10.1038 /$ npp. 2011.183

Sakai, Y., Kumano, H., Nishikawa, M., Sakano, Y., Kaiya, H., Imabayashi, E., et al. (2006). Changes in cerebral glucose utilization in patients with panic disorder treated with cognitive-behavioral therapy. NeuroImage 33, 218-226. doi: 10.1016/j.neuroimage.2006.06.017

Salone, A., Di Giacinto, A., Lai, C., De Berardis, D., Iasevoli, F., Fornaro, M., et al. (2016). The interface between neuroscience and neuropsychoanalysis: focus on brain connectivity. Front. Hum. Neurosci. 10:20. doi: $10.3389 /$ fnhum.2016.00020

Samson, A. C., Meisenzahl, E., Scheuerecker, J., Rose, E., Schoepf, V., Wiesmann, M., et al. (2011). Brain activation predicts treatment improvement in patients with major depressive disorder. J. Psychiat. Res. 45, 1214-1222. doi: 10.1016/j.jpsychires.2011.03.009

Schienle, A., Schäfer, A., Hermann, A., Rohrmann, S., and Vaitl, D. (2007). Symptom provocation and reduction in patients suffering from spider phobia. Eur. Arch. Psychiatry Clin. Neurosci. 257, 486-493. doi: 10.1007/s00406-007-0754-y

Seedat, S., Warwick, J., van Heerden, B., Hugo, C., Zungu-Dirwayi, N., Van Kradenburg, J., et al. (2004). Single photon emission computed tomography in posttraumatic stress disorder before and after treatment with a selective serotonin reuptake inhibitor. J. Affect. Disord. 80, 45-53. doi: 10.1016/S0165-0327(03)00047-8

Siegle, G. J., Thompson, W., Carter, C. S., Steinhauer, S. R., and Thase, M. E. (2007). Increased amygdala and decreased dorsolateral prefrontal BOLD responses in unipolar depression: related and independent features. Biol. Psychiat. 61 , 198-209. doi: 10.1016/j.biopsych.2006.05.048

Stahl, S. M. (2013). Stahl's Essential Psychopharmacology: Neuroscientific Basis and Practical Applications. Cambridge: Cambridge University Press.

Stein, M. B., Simmons, A. N., Feinstein, J. S., and Paulus, M. P. (2007). Increased amygdala and insula activation during emotion processing in anxiety-prone subjects. Am. J. Psychiatry 164, 318-327. doi: 10.1176/ajp.2007.164.2.318

Timary, P. D., Heenen-Wolff, S., and Philippot, P. (2011). The question of "Representation" in the psychoanalytical and cognitive-behavioral approaches. Some theoretical aspects and therapy considerations. Front. Psychol. 2:71. doi: 10.3389/fpsyg.2011.00071

Vlassenko, A., Sheline, Y. I., Fischer, K., and Mintun, M. A. (2004). Cerebral perfusion response to successful treatment of depression with different serotoninergic agents. J. Neuropsychiatry Clin. Neurosci. 16, 360-363. doi: 10.1176/jnp.16.3.360

Wager, T. D., Davidson, M. L., Hughes, B. L., Lindquist, M. A., and Ochsner, K. N. (2008). Prefrontal subcortical pathways mediating successful emotion regulation. Neuron 59, 1037-1050. doi: 10.1016/j.neuron.2008.09.006

Warwick, J. M., Carey, P., Van der Linden, G., Prinsloo, C., Niehaus, D., Seedat, S., et al. (2006). A comparison of the effects of citalopram and moclobemide on resting brain perfusion in social anxiety disorder. Metab. Brain Dis. 21, 241-252. doi: 10.1007/s11011-006-9009-2

Weightman, M. J., Air, T. M., and Baune, B. T. (2014). A review of the role of social cognition in major depressive disorder. Front. Psychiatry 5:179. doi: 10.3389/fpsyt.2014.00179 
Wiswede, D., Taubner, S., Buchheim, A., Münte, T. F., Stasch, M., Cierpka, M., et al. (2014). Tracking functional brain changes in patients with depression under psychodynamic psychotherapy using individualized stimuli. Plos ONE 9:e109037. doi: 10.1371/journal.pone.0109037

Yoshimura, S., Okamoto, Y., Onoda, K., Matsunaga, M., Okada, G., Kunisato, Y., et al. (2014). Cognitive behavioral therapy for depression changes medial prefrontal and ventral anterior cingulate cortex activity associated with self-referential processing. Soc. Cogn. Affect. Neurosci. 9, 487-493. doi: 10.1093/scan/nst009

Zilles, K., Armstrong, E., Schleicher, A., and Kretschmann, H. J. (1988). The human pattern of gyrification in the cerebral cortex. Anat. Embryol. 179, 173-179. doi: 10.1007/BF00304699
Conflict of Interest Statement: The authors declare that the research was conducted in the absence of any commercial or financial relationships that could be construed as a potential conflict of interest.

Copyright (c) 2017 Kalsi, Altavilla, Tambelli, Aceto, Trentini, Di Giorgio and Lai. This is an open-access article distributed under the terms of the Creative Commons Attribution License (CC BY). The use, distribution or reproduction in other forums is permitted, provided the original author(s) or licensor are credited and that the original publication in this journal is cited, in accordance with accepted academic practice. No use, distribution or reproduction is permitted which does not comply with these terms. 